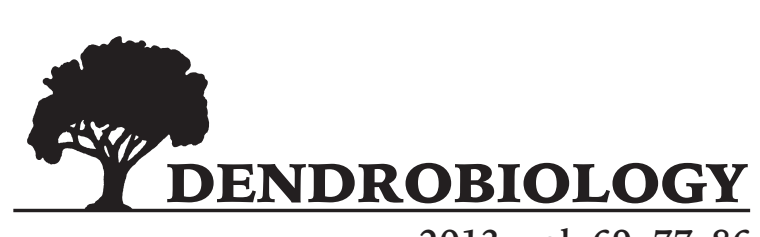

2013, vol. $69,77-86$

\author{
Teresa Hazubska-Przybyt, Ewelina Ratajczak, \\ Ewa Marzena Kalemba, Krystyna Bojarczuk
}

\title{
Growth regulators and guaiacol peroxidase activity during the induction phase of somatic embryogenesis in Picea species
}

\author{
Received: 2 August 2012; Accepted 22 October 2012
}

\begin{abstract}
Biochemical studies during the induction phase of somatic embryogenesis in Picea abies [L.] Karst. and P. omorika [Pančić] Purk. can supplement our basic knowledge of the developmental processes accompanying the formation of embryogenic tissues from explants. Such studies may also contribute to finding the markers specific to the early stages of somatic embryogenesis of spruce species and, consequently, to the optimization of the process of initiation of embryogenic tissues from different types of plant explants treated with various growth regulator combinations.

In this paper the effect of certain growth regulator systems on enzymatic activity was studied. The analysis of guaiacol peroxidase activity (EC 1.11.1.7), based on the spectrophotometric method, showed that this activity was the lowest in mature zygotic embryos (explants) and significantly higher in 8-week-old embryogenic and non-embryogenic calluses treated with various combinations of growth regulators. In the newly initiated embryogenic tissue, the activity of this enzyme decreased and remained at a lower level during proliferation, irrespective of the applied growth regulator combination. The type and concentration of growth regulators used for the initiation and proliferation of embryogenic tissues had no statistically significant effect on peroxidase activity, although during the initiation often its increased level was observed in calluses treated with 2.4-D.

Detection of guaiacol peroxidase activity in the induction phase of somatic embryogenesis proves its participation in this process. The subsequent change in its activity indicates that this peroxidase can be a biochemical marker of somatic embryogenesis of the tested spruce species.
\end{abstract}

Additional key words: spruce, embryogenic tissue, auxins, peroxidase

Address: T. Hazubska-Przybył, E. Ratajczak, E.M. Kalemba, K. Bojarczuk, Polish Academy of Sciences, Institute of Dendrology, Parkowa 5, 62-035 Kórnik, Poland, e-mail: hazubska@o2.pl

\section{Introduction}

Somatic embryogenesis is the process of somatic cells acquiring embryogenic competence under specific conditions. These cells undergo a series of morphological, physiological, molecular and biochemical changes that lead to the formation of somatic em- bryos (Quiroz-Figueroa et al. 2006). The process of somatic embryogenesis can be controlled and regulated in vitro.

Embryogenic tissue of coniferous tree species is usually initiated from immature or mature zygotic embryos taken from seeds (Vágner et al. 2005; Pullman et al. 2009). Explants are placed in media con- 
taining growth regulators (i.e., plant growth regulators), which are usually auxins and cytokinins (Vágner et al. 2005), or as in the case of firs, cytokinins alone (Salajova et al. 1998), at a suitable concentration to initiate somatic embryogenesis. The type and physiological status of explants and the type and concentration of growth regulators are among the main factors determining the acquisition of embryogenic competence by plant cells in vitro, although genetic factors also affect this process (Namasivayam 2007).

Somatic embryogenesis can be divided into induction and expression phases. In the induction phase, the somatic cells of explants acquire embryogenic competence (initiation stage) and proliferate as embryogenic cells (proliferation stage). In the expression phase, the embryogenic cells differentiate into somatic embryos (Namasivayam 2007). Jimenez (2001) suggests that these two phases (induction and expression) are independent of each other and influenced by different factors.

The acquisition of embryogenic competence by vegetative cells and the further development of somatic embryos are associated with many biochemical changes, which often result from the influence of plant growth regulators added to the medium at various stages of the culture. These changes are reflected e.g. in differences in the activity of specific enzymes closely related to the different phases of somatic embryo development: from the initiation of embryogenic tissue (ET) from explants to the formation of complete plants (Mo et al. 1996; Kormuták et al. 2003; Quiroz-Figueroa et al. 2006). Some of the enzymes which activity often changes during somatic embryogenesis in plants are peroxidases (Krsnik-Rasol 1991; de Klerk 1997; Stasolla and Yeung 2007). Peroxidases (EC 1.11.1.7) belong to the group of oxidoreductases, catalyzing hydrogen peroxide oxidation of various substrates. In plant cells, peroxidase isoenzymes are located in the cell wall and vacuole (Carpin et al. 1999). They participate in the antioxidant system, protecting cells from excessive accumulation of hydrogen peroxide and pathogen attack (Sutherland 1991) as well as in plant cell development (Brownleader et al. 2000; Cordewener et al. 1991), e.g. in somatic embryos of coniferous tree species (Mo et al. 1996; Kormuták et al. 2003).

The aim of this study was to determine whether guaiacol peroxidase is active during the induction phase of somatic embryogenesis in P. abies [L.] Karst. and P. omorika [Pančić] Purk. and if the type or concentration of growth regulator combinations affects the level of its activity and the level of ET initiation and proliferation.

\section{Material and methods}

\section{ET initiation and peroxidase activity}

Cones of Picea abies and P. omorika were collected from the local experimental forest Zwierzyniec (provenance Kolonowskie) and from the Arboretum in Kórnik near Poznań (Poland) in October 2009, respectively. The seeds were stored at $4^{\circ} \mathrm{C}$ for $2-3$ months. After this time, the seeds were sterilized for $10 \mathrm{~min}$ utes in $33 \%$ (v/v) $\mathrm{H}_{2} \mathrm{O}_{2}$ (hydrogen peroxide solution) with addition of two drops of Tween 20, rinsed three times in sterile distilled water and stored in fresh water for $14-16$ hours in the dark at $4^{\circ} \mathrm{C}$. Mature zygotic embryos were excised from the seeds and placed on $1 / 2$ LM medium (with $1 / 2$ of full concentrations of media recommended by Litvay et al. 1985) to initiate ET. We tested the influence on ET initiation frequency of nine combinations of growth regulators added to the medium:

A) $9 \mu \mathrm{M} 2.4-\mathrm{D}+2.2 \mu \mathrm{M}$ BA, abbreviated as 2.4-D/BA2.2

B) $9 \mu \mathrm{M} 2.4-\mathrm{D}+4.5 \mu \mathrm{M}$ BA, abbreviated as 2.4-D/BA4.5

C) $9 \mu \mathrm{M} 2.4-\mathrm{D}+8.8 \mu \mathrm{M}$ BA, abbreviated as 2.4-D/BA8.8

D) $9 \mu \mathrm{M}$ NAA $+2.2 \mu \mathrm{M}$ BA, abbreviated as NAA/BA2.2

E) $9 \mu \mathrm{M}$ NAA $+4.5 \mu \mathrm{M}$ BA, abbreviated as NAA/BA4.5

F) $9 \mu \mathrm{M}$ NAA $+8.8 \mu \mathrm{M}$ BA, abbreviated as NAA/BA8.8

G) $9 \mu \mathrm{M}$ picloram $+2.2 \mu \mathrm{M}$ BA, abbreviated as picloram/BA2.2

H) $9 \mu \mathrm{M}$ picloram $+4.5 \mu \mathrm{M} \mathrm{BA}$, abbreviated as picloram/BA4.5

I) $9 \mu \mathrm{M}$ picloram $+8.8 \mu \mathrm{M}$ BA, abbreviated as picloram/BA8.8

Combinations B, E and $\mathrm{H}(9 \mu \mathrm{M}$ auxin and $4.5 \mu \mathrm{M}$ BA) can be considered as control treatments because in previous experiments, we obtained the best results for ET initiation and proliferation when using these combinations (data not shown). All of the media were also supplemented with sucrose $\left(10 \mathrm{~g} \cdot \mathrm{dm}^{-3}\right)$ and solidified with Phytagel $\left(5 \mathrm{~g} \cdot \mathrm{dm}^{-3}\right.$; Sigma-Aldrich, Poznań, Poland). The pH of the media was 5.8. The explants were incubated at $22 \pm 1^{\circ} \mathrm{C}$ in darkness.

The following samples of plant material (fresh weight) were collected for guaiacol peroxidase activity analysis: mature zygotic embryos excised from seeds (which were the source explants), 8-week-old non-embryogenic calluses (NC), embryogenic calluses (EC), in which originated from explants, and embryogenic tissue (ET) from EC (Fig. 1). The samples consisted of 2-5 explants in three repeats for each growth regulator combination. 

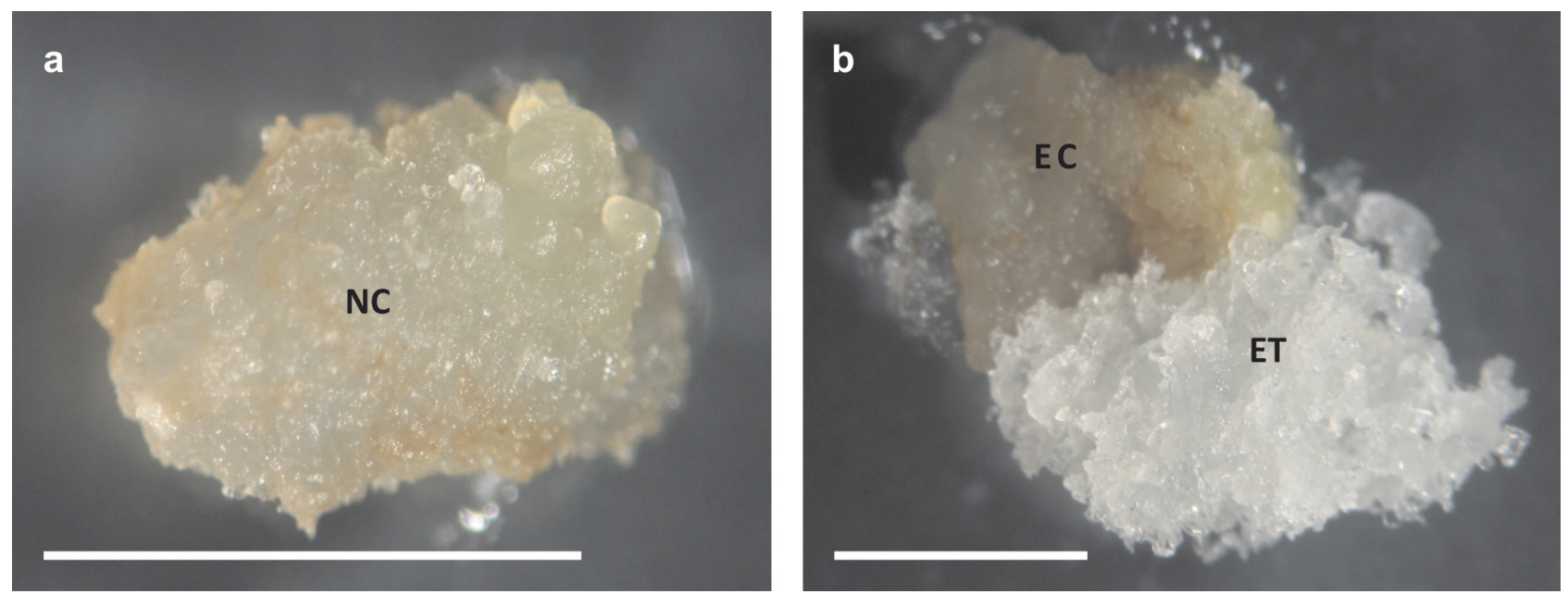

Fig. 1. Eight-week-old non-embryogenic callus (NC) of Picea omorika (a) and embryogenic callus (EC) with embryogenic tissue $(\mathrm{ET})(\mathrm{b})$

\section{ET proliferation and peroxidase activity}

Following ET initiation, we collected several lines of tissues to be proliferated in $1 / 2 \mathrm{LM}$ medium supplemented with $9 \mu \mathrm{M}$ picloram and $4.5 \mu \mathrm{M} \mathrm{BA}$, which is routinely used for this purpose in our laboratory. ET was incubated at $22 \pm 1^{\circ} \mathrm{C}$ in darkness. After two months of proliferation, we selected the two best-growing lines (one for Picea abies and one for $P$. omorika), and we tested the influence of the same nine growth regulator combinations as described previously, added into $1 / 2 \mathrm{LM}$ medium, on ET weight on days 7, 14 and 21 of culture. Finally, on day 21 of culture, we measured peroxidase activity in ET treated with these growth regulator combinations. Clumps of ET from each growth regulator combination treatment were collected for these analyses; three repeats were performed.

\section{Enzyme extraction and assay}

The samples (0.2g each) of mature zygotic embryos, 8-week-old calluses (NC and EC) or ET collected from the nine different growth regulator combinations were ground in liquid nitrogen and homogenized in $50 \mathrm{mM}$ sodium phosphate buffer, $\mathrm{pH}$ 7.0, containing $0.2 \mathrm{mM}$ EDTA and $20 \%$ polyvinylpolypyrrolidone (PVPP). The homogenates were centrifuged at $4^{\circ} \mathrm{C}$ at $20,000 \times g$ for $20 \mathrm{~min}$, and the supernatants were analyzed.

Guaiacol peroxidase (POX, EC 1.11.1.7) activity was measured spectrophotometrically in the guaiacol oxidation reaction at $470 \mathrm{~nm}$ for $1 \mathrm{~min}$ at $20^{\circ} \mathrm{C}$ (using an extinction coefficient of $\stackrel{a}{=}=26.6 \mathrm{mM} / \mathrm{cm}$ ) according to Chance and Maehly (1955). The reaction mixture contained $1 \mathrm{ml}$ of $0.1 \mathrm{M}$ phosphate buffer, $\mathrm{pH}$ 7.0, $1 \mathrm{ml}$ of $1 \%$ guaiacol, $1 \mathrm{ml}$ of $0.2 \mathrm{M} \mathrm{H}_{2} \mathrm{O}_{2}$ and $12-25 \mu \mathrm{l}$ of the enzyme extract. Control assays were performed replacing the enzyme extracts or sub- strates with buffer. The reaction started by adding $\mathrm{H}_{2} \mathrm{O}_{2}$. POX activity was expressed as nkat $\mathrm{min}^{-1} \mathrm{mg}^{-1}$ protein. The results correspond to the means ${ }^{+}$. s.d. of the values obtained with three different extracts and six measurements per extract. Protein content of crude enzyme extracts was estimated according to Bradford (1976), using bovine serum albumin (BSA) as a standard.

\section{Embryogenic potential of the tested lines}

To test the ability of the lines of the two Picea species to regenerate somatic embryos, the embryogenic tissues were proliferated in $1 / 2 \mathrm{LM}$ medium supplemented with $9 \mu \mathrm{M}$ picloram and $4.5 \mu \mathrm{M} \mathrm{BA}$ and subsequently cultured in the same medium but without growth regulators and with the addition $10 \mathrm{~g} \cdot \mathrm{dm}^{-3}$ activated charcoal (Sigma-Aldrich, Poznań, Poland). After one week, ET was transferred to $1 / 2 \mathrm{LM}$ maturation medium supplemented with $40 \mu \mathrm{M}$ ABA (abscisic acid) and $1 \mu \mathrm{M}$ IBA (indolile-3-butyric acid). The cultures were maintained at $22 \pm 1^{\circ} \mathrm{C}$ under a $16 \mathrm{~h}$ photoperiod. The photon flux was $35 \mu \mathrm{mol} \mathrm{m} \mathrm{m}^{-2} \mathrm{~s}^{-1}$. The total number of somatic embryos and the number of cotyledonary embryos per 1 gram fresh weight of embryogenic tissue were assessed after 5 weeks of culture in this medium.

\section{Data analysis}

Data concerning ET induction were analyzed using the $\chi^{2}$ test $(\mathrm{p}<0.05)$. One-way ANOVA based on the Tukey test $(\mathrm{p}<0.05)$ was used to assess differences in peroxidase activity between the compared variants at the ET proliferation and somatic embryo maturation stages (STATISTICA software, StatSoft Polska, Kraków, 1995-2005). 


\section{Results}

\section{ET initiation and peroxidase activity}

Initiation of ET from mature zygotic embryos of both spruce species was achieved, irrespective of the growth regulator combinations added to the $1 / 2 \mathrm{LM}$ medium (Table 1). The highest ET initiation frequency in Picea abies was $13.00 \%$ for picloram/BA4.5, whereas in P. omorika, it was $12.22 \%$ for $2.4-\mathrm{D} / \mathrm{BA} 8.8$. The lowest ET initiation was obtained for the combination NAA/BA8.8 in both spruce species. There were no statistically significant differences in the ET initiation frequency for Picea abies and P. omorika explants cultured in the presence of various BA concentrations with various auxin types.

In the mature zygotic embryos of both spruce species used to initiate the embryogenic cultures, very low peroxidase activity was detected $(0.0005 \pm 0.0$ units/FW; data not shown). The level of peroxidase activity in 8-week-old explants of both spruce species increased and varied depending on the growth regulator combinations added to the initiation medium (Fig. 2). In Picea abies, the activity was the highest for explants treated with 2.4-D/BA2.2 (Fig. 2a). The lowest activity of peroxidase was noted for picloram/BA8.8 (Fig. 2c). In 8-week-old P. omorika calluses, high peroxidase activity was observed under the 2.4-D/BA8.8 treatment (Fig. 2a). A low activity of the enzyme was noted for NAA/BA4.5 and NAA/BA8.8 (Fig. 2b) as well as picloram/BA2.2 and picloram/BA4.5 (Fig. 2c).

The differences in peroxidase activity between embryogenic and non-embryogenic calluses (EC and NC) after 8 weeks of culture were usually low, regardless of the growth regulator combinations (Fig. 2). However, in some cases, significant differences in peroxidase activity were observed between EC and NC of both spruce species treated with the same growth regulator combinations (Fig. 2).

In general, peroxidase activity in Picea abies calluses (NC and EC) ranged from approximately 50 to 280 units (Fig. 2), while for P. omorika explants, it was lower and ranged from 15 to 150 units (Fig. 2), regardless of the ability of the calluses to form ET. The greatest difference in peroxidase activity was detected between $P$. abies calluses (EC and $\mathrm{NC}$ ) for NAA/BA8.8. The difference reached the level of 175.7 units (Fig. 2b). Significant differences in peroxidase activity was also observed in case of calluses (NC and EC) growing in the presence of 2.4-D/BA2.2 (Fig. 2a) and picloram/BA4.5 (Fig. 2c). These differences were 135.9 and 152.2 units, respectively. Peroxidase activity was higher for NC than for EC in these cases (Fig. 2a,c). Additionally, for these growth regulator combinations, the highest frequencies were obtained for the initiation of ET from ma-

Table 1. Embryogenic tissue (ET) initiation from mature zygotic embryos of Picea abies and P. omorika in $1 / 2$ LM medium supplemented with various growth regulator combinations

\begin{tabular}{|c|c|c|c|c|c|}
\hline Species & Auxin $(9 \mu \mathrm{M})$ & $\mathrm{BA}(\mu \mathrm{M})$ & $\begin{array}{l}\text { Final number } \\
\text { of explants }\end{array}$ & $\begin{array}{c}\text { Zygotic embryos } \\
\text { with ET }(\%)\end{array}$ & $\chi^{2} P$ \\
\hline \multirow[t]{9}{*}{ Picea abies } & 2.4-D & 2.2 & $n=50$ & $10.00 \pm 0.30$ & 0.17 \\
\hline & & 4.5 & $n=50$ & $8.00 \pm 0.27$ & 0.9208 \\
\hline & & 8.8 & $n=50$ & $8.00 \pm 0.27$ & \\
\hline & NAA & 2.2 & $n=50$ & $4.00 \pm 0.20$ & 4.79 \\
\hline & & 4.5 & $n=50$ & $12.00 \pm 0.33$ & 0.0908 \\
\hline & & 8.8 & $n=50$ & $2.00 \pm 0.14$ & \\
\hline & picloram & 2.2 & $n=50$ & $6.00 \pm 0.24$ & 1.43 \\
\hline & & 4.5 & $n=46$ & $13.00 \pm 0.34$ & 0.4882 \\
\hline & & 8.8 & $n=46$ & $8.70 \pm 0.28$ & \\
\hline \multirow[t]{9}{*}{ P. omorika } & 2.4-D & 2.2 & $n=41$ & $2.44 \pm 0.16$ & 3.36 \\
\hline & & 4.5 & $n=50$ & $8.00 \pm 0.27$ & 0.1863 \\
\hline & & 8.8 & $n=49$ & $12.22 \pm 0.33$ & \\
\hline & NAA & 2.2 & $n=50$ & $8.00 \pm 0.27$ & 3.36 \\
\hline & & 4.5 & $n=49$ & $10.20 \pm 0.31$ & 0.1860 \\
\hline & & 8.8 & $n=50$ & $2.00 \pm 0.14$ & \\
\hline & picloram & 2.2 & $n=50$ & $4.00 \pm 0.20$ & 0.29 \\
\hline & & 4.5 & $n=50$ & $4.00 \pm 0.20$ & 0.8656 \\
\hline & & 8.8 & $n=50$ & $6.00 \pm 0.24$ & \\
\hline
\end{tabular}

Data are means \pm SD of two experiments consisting of five replicates each, $n=50$. Final number of explants $=$ explants not contaminated. 2.4-D - 2.4-dichlorophenoxyacetic acid; NAA - 1-naphtaleneacetic acid; picloram - 4-amino-3.6.6-trichloropicolinic acid; BA 6-benzyladenine; ET - embryogenic tissue 
ture zygotic embryos, which were $10.00 \%$ and $13.00 \%$, respectively (Table 1 ).

The greatest differences in peroxidase activity between Picea omorika calluses (NC and EC) were observed for NAA/BA2.2 or NAA/BA8.8 (Fig. 2b) and 2.4-D/BA2.2 (Fig. 2a). The differences were 81.9, 45.3 and 40.4 units, respectively (Fig. 2). In all of these cases, the peroxidase activity associated with NC was higher than for EC (Fig. 2a, b). However, the ET initiation frequencies for these growth regulator combinations were $8.00 \%, 2.00 \%$ and $2.44 \%$, respec-

\section{Picea abies}

a)

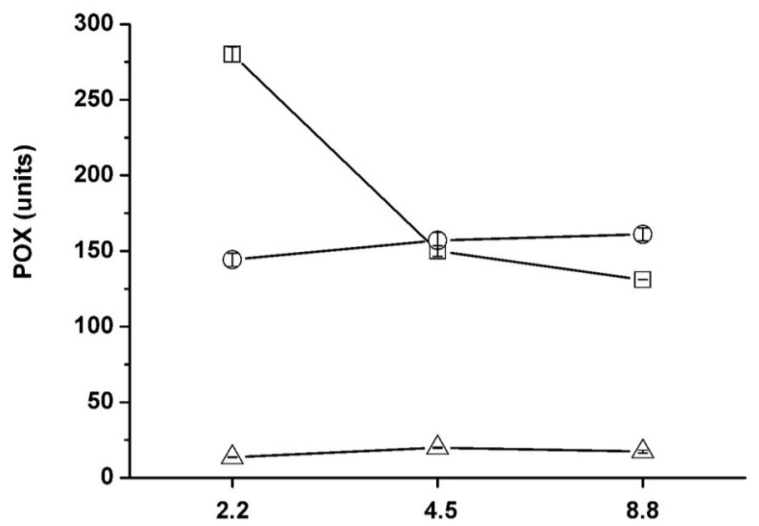

b)

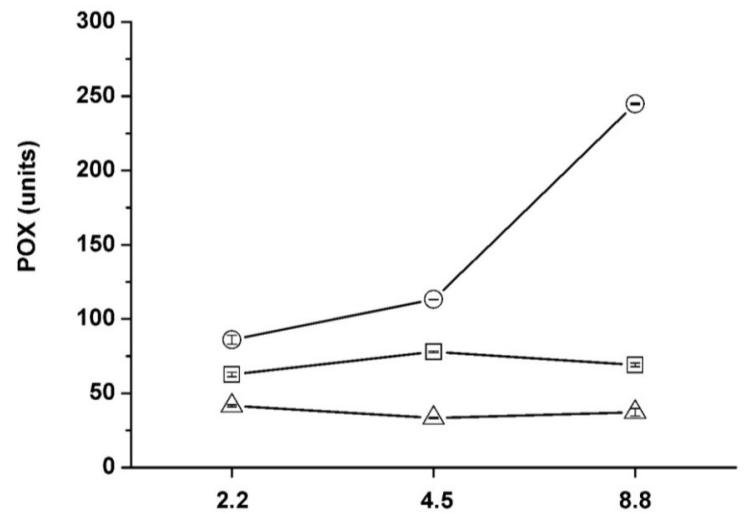

c)

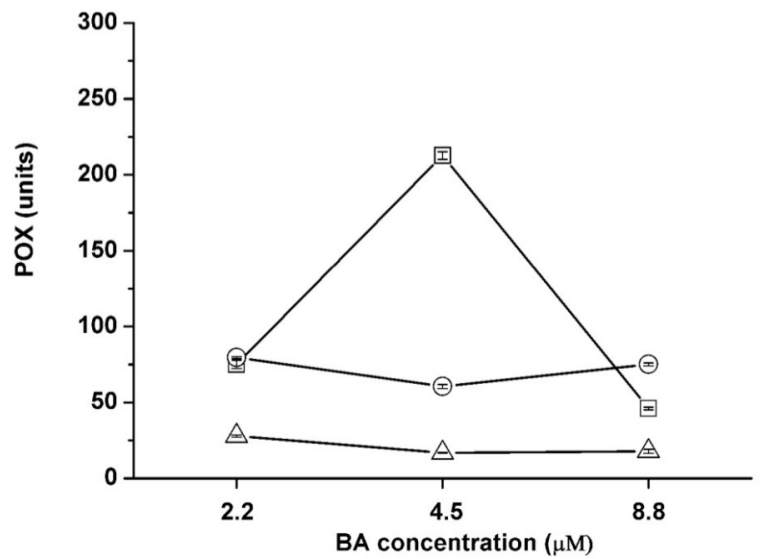

tively, and did not reach the highest values, in contrast to what was observed for the Norway spruce (Table 1). The highest ET initiation frequency from mature zygotic embryos of $P$. omorika was noted for 2.4-D/BA8.8 (12.22\%) and NAA/BA4.5 (10.20\%). However, the differences in peroxidase activity between $P$. omorika calluses (NC and EC) were very low under these growth regulator combinations, at 7.4 (Fig. 2a) and 7.3 units (Fig. 2b), respectively. It must be emphasized that the highest ET initiation frequencies for this spruce species were associated with both
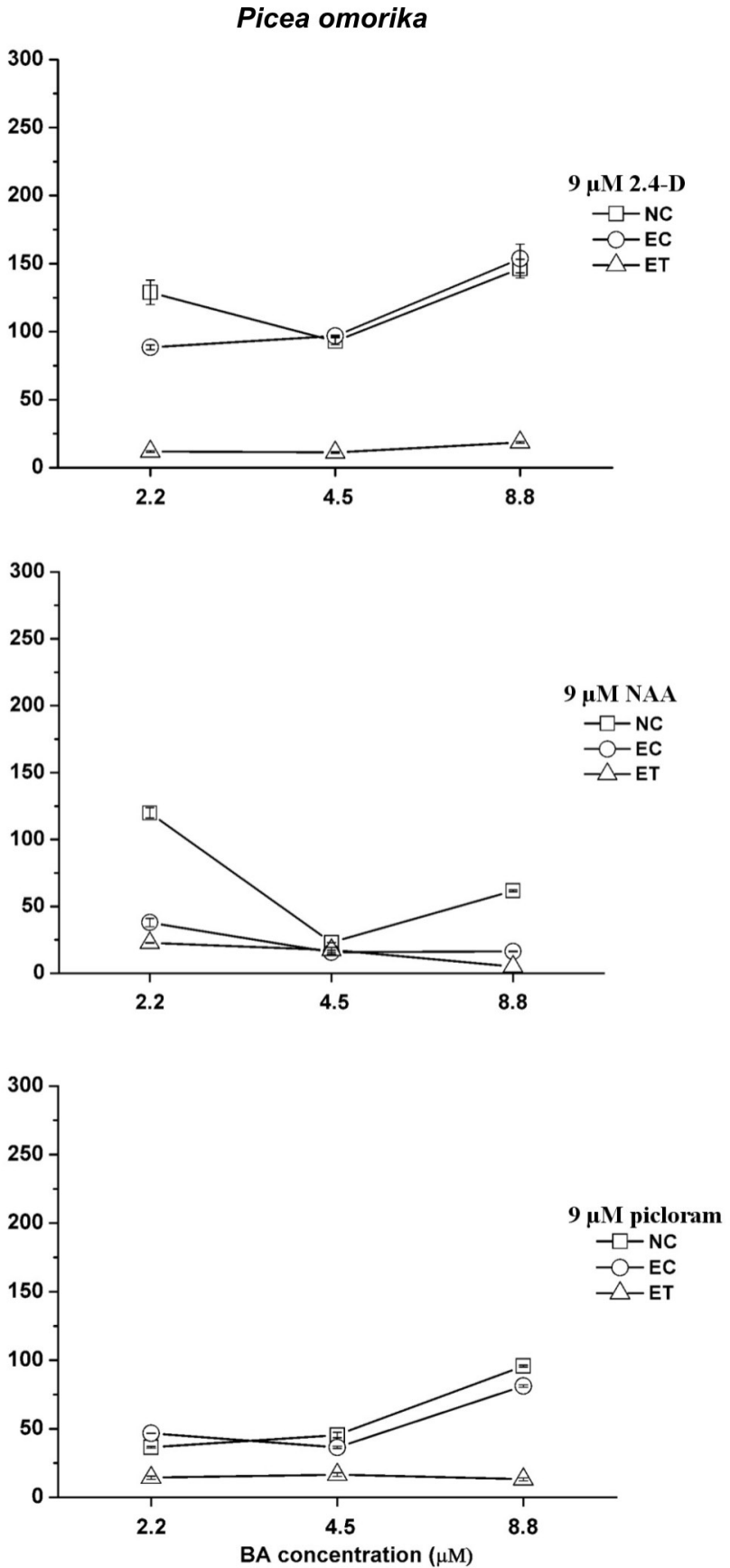

Fig. 2. Peroxidase (POX) activity in Picea abies and P. omorika 8-week-old callus (NC), embryogenic callus (EC) and embryogenic tissue (ET) cultured in $1 / 2 \mathrm{LM}$ medium supplemented with various BA concentration and a) $9 \mu \mathrm{M}$ 2.4-D, b) $9 \mu \mathrm{M} \mathrm{NAA,} \mathrm{c)} 9 \mu \mathrm{M}$ picloram. 1 unit $=1$ nkatmin ${ }^{-1}$ mgprot $^{-1}$. Means $\pm \mathrm{SD}, \mathrm{n}=3$ 
high and low peroxidase activities in NC and EC (Table 1, Fig. 2a, b).

The activity of peroxidase in the newly initiated embryogenic tissue (ET) from 8-week-old calluses of Picea abies and $P$. omorika was generally lower than in the callus itself (EC), regardless of the auxin type and BA concentrations added to the initiation medium (Fig. 2). The activity level of this enzyme was the same between ET and the callus from which it was generated only in $P$. omorika when the initiation medium was supplemented with NAA/BA4.5 (Fig. 2b).

Picea abies
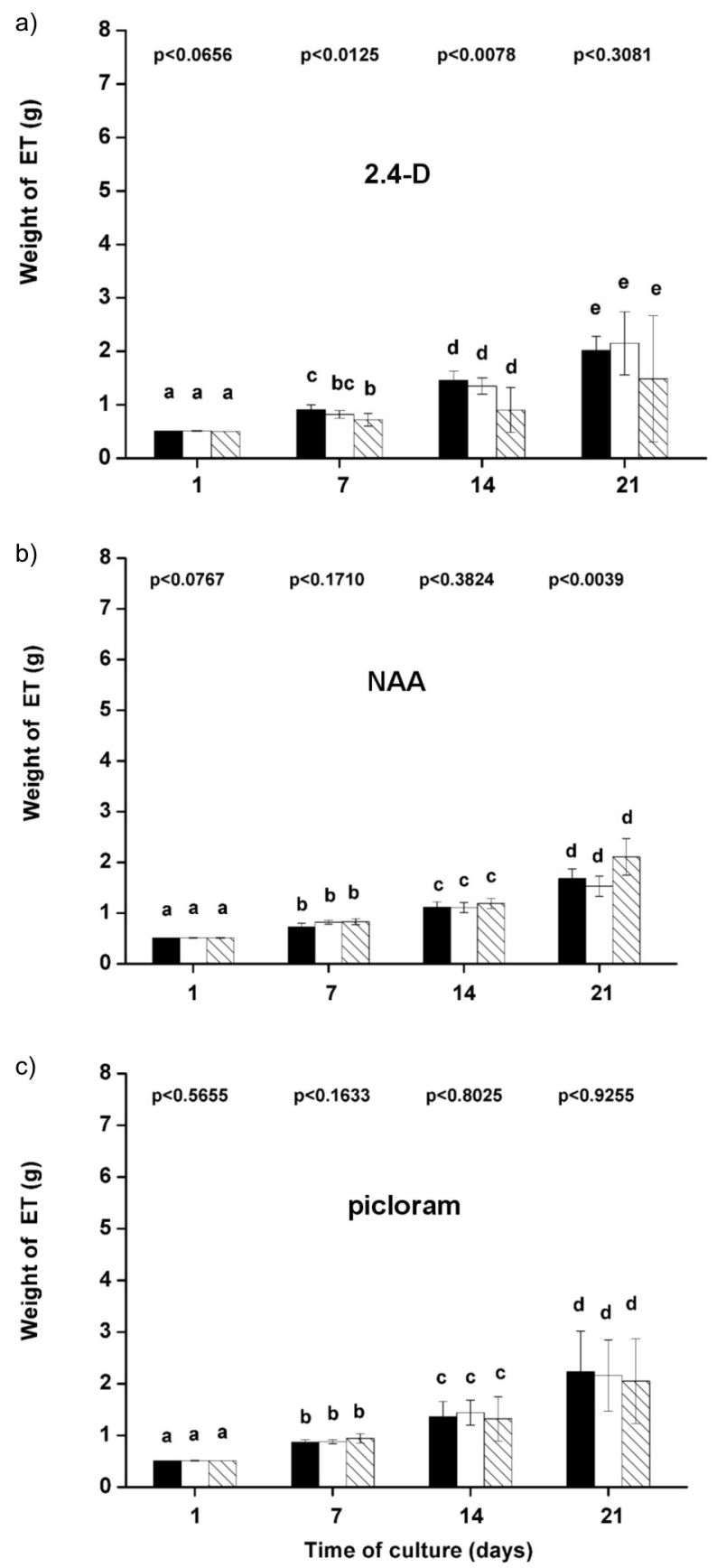

\section{ET proliferation and peroxidase activity}

ET proliferation was achieved for both Norway and Serbian spruce for all growth regulator combinations. However, the ET weight was generally lower for Picea abies compared to $P$. omorika ET on days 14-21 of culture (Fig. 3). The highest $P$. abies ET weight of $2.23 \mathrm{~g}$, observed on day 21 of culture, was achieved in the media supplemented with picloram and BA at concentration $2.2 \mu \mathrm{M}$ (Fig. 3c), whereas the lowest weight of $1.48 \mathrm{~g}$ was observed under the 2.4-D/BA8.8 treat-

\section{Picea omorika}
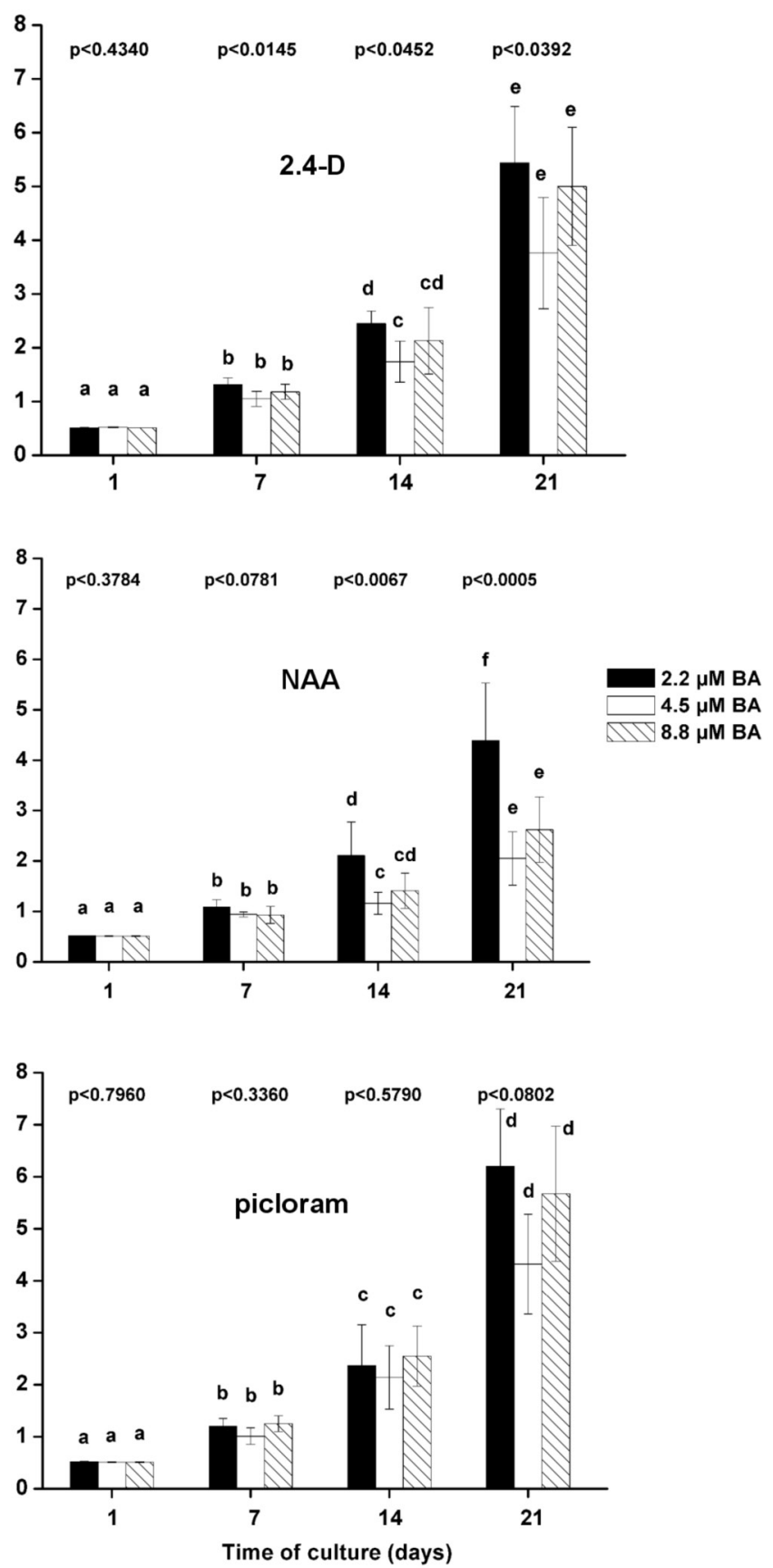

Fig. 3. Picea abies and P. omorika embryogenic tissue (ET) weight during 21 days of culture in $1 / 2$ LM medium supplemented with a) $9 \mu \mathrm{M} 2.4-\mathrm{D}$, b) $9 \mu \mathrm{M}$ NAA, c) $9 \mu \mathrm{M}$ picloram and following concentrations $2.2 \mu \mathrm{M}, 4.5 \mu \mathrm{M}, 8.8 \mu \mathrm{M}$ of $\mathrm{BA}$ in each variant. Means $\pm \mathrm{SD}, \mathrm{n}=6$ 

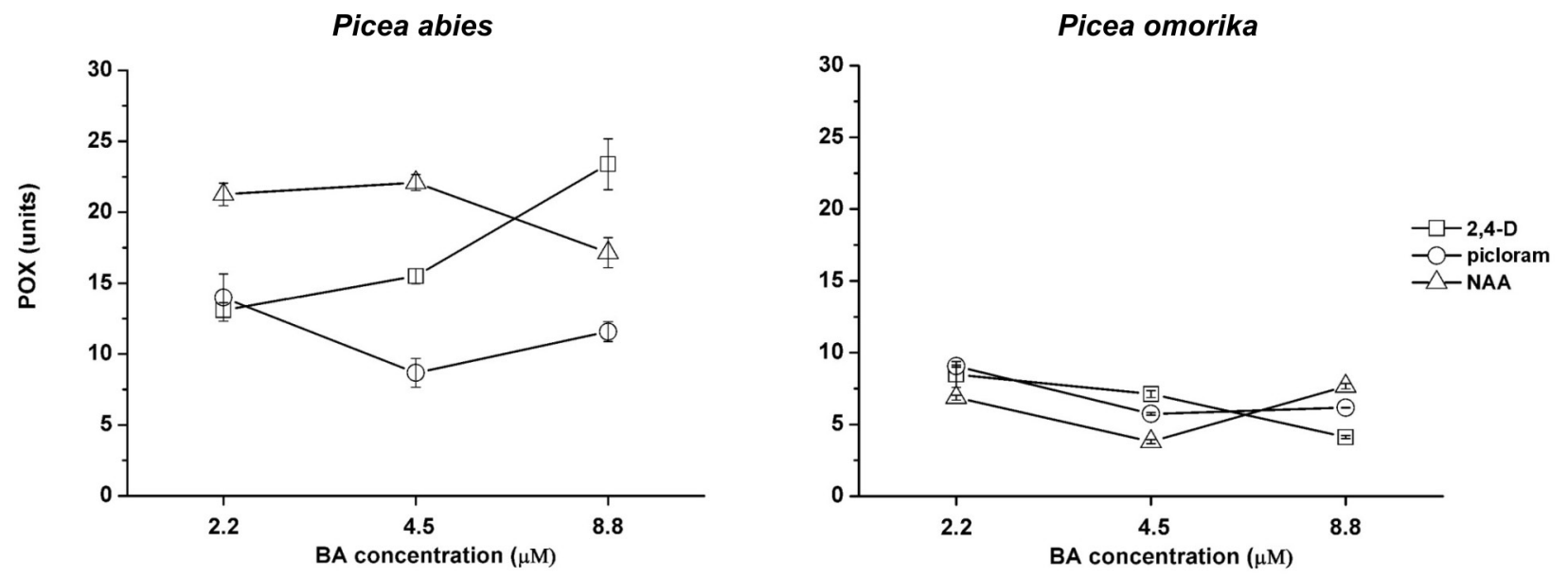

Fig. 4. Effect of hormone combinations on peroxidase (POX) activity in Picea abies and P. omorika embryogenic tissue (ET) proliferated for $1-21$ days in $1 / 2 \mathrm{LM}$ medium with $9 \mu \mathrm{M} 2.4-\mathrm{D}$, NAA, picloram and $2.2 \mu \mathrm{M}-8.8 \mu \mathrm{M}$ BA. Means $\pm \mathrm{SD}, \mathrm{n}=3$

ment (Fig. 3a). On day 21 of culture, no statistically significant differences in $P$. abies ET proliferation were detected.

The highest $P$. omorika ET weight, on day 21 of culture, was usually obtained in the medium supplemented with $2.2 \mu \mathrm{M} \mathrm{BA}$, irrespective of the type of auxins added to the proliferation medium (Fig. 3). It ranged from $4.39 \mathrm{~g}$ for NAA (Fig. 3b) to $6.20 \mathrm{~g}$ for picloram (Fig. 3c). The lowest ET weight was observed in the medium supplemented with NAA/BA4.5 (Fig. 3b). Statistically significant differences in P. omorika ET proliferation on day 21 of culture were detected under combinations of NAA with various BA concentrations (Fig. 3b).

On day 21 of culture, varied peroxidase activity levels were found in ET for both of the tested spruce species exposed to the specific growth regulator combinations. The peroxidase activity in $P$. abies ET was usually higher (more than 10 units) than in P. omorika ET (Fig. 4). The highest peroxidase activity in P. abies ET was found in the medium supplemented with 2.4-D/BA8.8 (Fig. 4). The lowest activity was observed in ET cultured with picloram/BA4.5 (Fig. 4). When the proliferation rates and peroxidase activities were compared for P. abies ET, on day 21 of culture, we noticed a trend of more rapid growth of tissue at a lower activity level of this enzyme (Fig. 3, Fig. 4). This was particularly evident for growth regulator combinations including 2.4-D (Fig. 3a, Fig. 4) or NAA (Fig. 3b, Fig. 4). The highest peroxidase activity in $P$. omorika ET was detected under the picloram/BA2.2 treatment (Fig. 4), while the lowest was associated with NAA/BA4.5 (Fig. 4). When the proliferation rates and peroxidase activities in $P$. omorika ET were compared on day 21 of culture, we observed a tendency to a better growth of the tissue when peroxidase activity was higher in most cases, in contrast to what was found for P. abies (Fig. 3, 4). An exception to this trend was observed for the culture of ET in the presence of $8.8 \mu \mathrm{M} \mathrm{BA}$ and $2.4-\mathrm{D}$ or picloram, where we observed a similar trend as in P. abies (Fig. 3a, c).

\section{Embryogenic potential of the tested lines}

Both the Picea abies and P. omorika ET lines presented the ability to produce somatic embryos. The $P$. abies lines regenerated 754 embryos/g fresh weight of embryogenic tissue on average, of which 92 were cotyledonary embryos (Table 2). P. omorika ET showed a lower embryogenic potential, regenerating $156 \mathrm{em}-$ bryos/g fresh weight of embryogenic tissue on average, including 3 cotyledonary embryos. The statistical analysis (the Tukey test) showed significant differences in the embryogenic potential between the tested lines of the two spruce species.

Table 2. Number of somatic embryos (per $1 \mathrm{~g}$ fresh weight of embryogenic tissue) after 5 weeks of incubation in maturation medium

\begin{tabular}{lcc}
\hline Species & Total embryos & $\begin{array}{c}\text { Cotyledonary } \\
\text { embryos }\end{array}$ \\
\hline Picea abies & $754 \mathrm{a} \pm 181.97$ & $92 \mathrm{a} \pm 30.51$ \\
$P$. omorika & $156 \mathrm{~b} \pm 47.52$ & $3 \mathrm{~b} \pm 1.53$ \\
$P$ & 0.0053 & 0.0072
\end{tabular}

Data are means \pm SD of three experiments consisting of three replicates each. Means followed by the various letter within column are significantly different (Tukey's test, $\mathrm{P}=0.05$ ) 


\section{Discussion}

In the present study, guaiacol peroxidase activity was found to be very low in mature zygotic embryos taken from seeds of both spruce species to induce embryogenic cultures (0.0005 \pm 0.0 units/FW; data not shown). After 8 weeks of culturing the explants in $1 / 2 \mathrm{LM}$ medium, peroxidase activity was detected in both callus types (NC and EC), regardless of the combinations of growth regulators added to the induction medium (Fig. 2). The highest peroxidase activity was generally detected in explants treated with 2.4-D and BA at various concentrations in both spruce species (Fig. 2a). For the other auxins and BA, this activity was slightly lower. We also observed that the peroxidase activity in embryogenic tissue (ET) of both spruce species was significantly lower in general than in 8-week-old calluses, regardless of the growth regulator combinations in the initiation medium (Fig. 2).

The reduction of peroxidase activity observed in mature zygotic embryos was probably a result of the dormancy reached by the seeds, inhibiting the germination process. A significant decrease in enzyme activity was also observed in Abies alba zygotic embryos reaching dormancy (Kormuták et al. 2003). In contrast, the corresponding peroxidase activity in somatic embryos at the maturation stage was three-fold higher compared to zygotic embryos. These authors also demonstrated that the peroxidase activity in non-embryogenic calluses (NC) of $A$. alba was much higher than in embryogenic tissues (ET). Similar results were obtained previously by Hřb et al. (1997), who demonstrated that high peroxidase activity in NC contrasted with the reduced number of isoperoxidases in the embryogenic suspensor mass. This was also confirmed in our study.

In the present study, embryogenic tissue of both spruce species was initiated by various combinations of all three tested types of auxins and BA at three different concentrations (Table 1). The ET initiation frequencies in Picea abies were high for all tested auxins, while in P. omorika, they were only high for 2.4-D and NAA. Various concentrations of BA, together with each type of auxin, had no significant effect on the ET initiation frequency of either spruce species (Table 1). We found that the peroxidase activity in 8-week-old calluses was highest in $P$. abies cultures treated with 2.4-D and 2.2 $\mu \mathrm{M}$ BA, reaching 280 units (Fig. 2). This result may indicate a more stressful effect of this growth regulator in comparison with the other two auxins, which were associated with significantly lower peroxidase activity.

The ET initiation process is affected by genetic determinants in explants, but it is also determined by culture conditions, especially the types and concentrations of growth regulators applied (Namasivayam 2007; Hazubska-Przybył and Bojarczuk 2008). Ac- cording to most protocols, somatic embryogenesis is usually induced by auxins (mostly 2.4-D) alone or in combination with cytokinins (Gaj 2004). Mainly auxins are agents that mediate the transition from somatic to embryogenic cells, but cytokinins also have an influence on this phenomenon (Jimenez 2001). Growth regulators added to initiation media contribute to the different changes observed in the physiology and gene expression of explant cells and, consequently, to the acquisition of embryogenic competence by vegetative cells (Feher et al. 2003; Namasivayam 2007). Embryogenic plant cultures are most commonly induced by $2.4-\mathrm{D}$ and less so by NAA or picloram. The most commonly used cytokinin for this purpose is BA (Jimenez 2001). Some growth regulators, such as 2.4-D, act not only as exogenous auxin analogues but also as stress factors (Gaj 2004) triggering an embryogenic pattern of development in cultured plant cells (Feher et al. 2003).

For certain growth regulator combinations, we found significant differences in peroxidase activity between calluses in which cells either acquired or did not acquire embryogenic competence (EC and NC), especially for Picea abies (Fig. 2a, c). In these cases, peroxidase activity was generally higher for NC. The exception to this pattern was $P$. abies calluses treated with NAA/BA8.8, where the situation was reversed (Fig. 2b). In the case of the two other combinations, the ET induction frequencies were also highest for this spruce species (Table 1), but it cannot be determined whether there was a directed change in the activity of peroxidase in EC that would lead to the acquisition of embryogenic competence by the cells of these calluses and, consequently, to an increase in the ET initiation frequency.

Exposure of explants to growth regulators is one of many factors that stimulates vegetative cells to change leading to the acquisition of embryogenic competence. The mechanisms underlying this change are still poorly understood. There is also no universally applicable signal that renders cells embryogenic (Mordhorst et al. 1997). Moreover, only a limited number of cells within an explant are able to follow the developmental pathway to become embryogenic (Toonen and de Vries 1996). This makes it more difficult to identify the mechanisms controlling this process.

Proliferation of embryogenic tissue of coniferous tree species is generally conducted in the same medium as the initiation of this tissue, usually with slight modification of the supplemented growth regulators, which are added in somewhat lower concentrations (Salajova et al. 1998; Stasolla et al. 2002). In the experiment presented in this report, ET proliferation was achieved for all of the tested growth regulator combinations, at both lower and higher doses of growth regulators, although the ET weight was 
higher for Picea omorika than for P. abies (Fig. 3). However, the best ET growth was generally obtained using a lower BA concentration $(2.2 \mu \mathrm{M})$, regardless of the type of auxin used. This situation was more evident for P. omorika (Fig. 3).

This research showed higher peroxidase activity in $P$. abies ET than in P. omorika ET (Fig. 4). Significant differences in the activity of this enzyme may be due to the different spruce species tested or different sensitivities of the tested embryogenic lines to the growth regulators used in the proliferation medium. In most cases, opposite trends were observed for the ET proliferation rate and peroxidase activity in the two spruce species, depending on the auxin type and BA concentration added to the medium. Picea abies ET presented more intensive growth at a lower peroxidase activity level, whereas $P$. omorika exhibited increased growth at a higher activity level of this enzyme. The exception to this trend was ET treated with $8.8 \mu \mathrm{M}$ BA, in which the trend was similar to that of $P$. abies. Thus, the combination of growth regulators affects the level of peroxidase activity in proliferating embryogenic tissues and, consequently, the intensity of tissue growth and the process of somatic embryogenesis. The different reactions of ET of the two spruce species to changes in the peroxidase activity level might result from the different abilities of the tested ET lines to form somatic embryos, with Picea abies tissue being found to be more efficient than that of $P$. omorika with respect to this process (Table 2). The embryogenic tissue of coniferous species do not present a homogenous structure but consists of so-called proembryos at several stages of development (Filonova et al. 2000). Only some of the most developed proembryos transform into somatic embryos. Hence, the peroxidase activity level in ET at the proliferation stage may be related to the number of the most developed proembryos present that are ready to initiate a new embryo development phase after the removal of auxin and cytokinin from the medium and treatment with abscisic acid (Stasolla et al. 2002).

The pattern of changes in guaiacol peroxidase activity observed in the present study in the induction phase of somatic embryogenesis in Picea abies and $P$. omorika indicate that this enzyme is related to this process.

The relationship between the growth regulator type added to the medium and the activity of peroxidase linked to somatic embryogenesis was more pronounced at the stage of proliferation than at the initiation stage of ET in both spruce species.

\section{Conclusions}

These studies presented the specificity effect of guaiacol peroxidase on somatic embryogenesis in the tested spruce species. We found that this peroxidase was active both in explants exposed to the chosen growth regulator systems and in embryogenic tissues. Guaiacol peroxidase activity was also detected in mature zygotic embryos used to establish the embryogenic cultures. In the two tested spruce species, the same pattern of guaiacol peroxidase activity was found, from the lowest level in explants to the highest in 8-week-old calluses. A moderate level was observed in the induced and proliferated embryogenic tissues, regardless of the composition of the growth regulators added to the culture media. The type and concentration of growth regulators used in the initiation and proliferation of embryogenic tissues had no statistically significant effect on peroxidase activity, although during the initiation often its increased level was observed in calluses treated with 2.4-D.

Detection of guaiacol peroxidase activity in the induction phase of somatic embryogenesis proves its participation in this process. The subsequent change in its activity indicate that this peroxidase can be a biochemical marker of somatic embryogenesis of the tested spruce species. But to confirm finally its role in this process, it is necessary to determine the pattern of guaiacol peroxidase in further studies.

\section{Acknowledgements}

The present study was supported by the National Science Centre in Kraków (grant no. N N309 130837), and by the Institute of Dendrology, Kórnik (statutory project), Poland. The Authors thank Mrs. Magdalena Sobczak for her precious technical assistance in the preparation of the present work.

\section{References}

Bradford M.M. 1976. A rapid and sensitive method for the quantitation of microgram quantities of protein utilizing the principle of protein-dye binding. Analytical Biochemistry 72: 248-254.

Brownleader M.D., Hopkins J., Mobasheri A., Dey P.M., Jackson P., Trevan M. 2000. Role of extension peroxidase in tomato (Lycopersicon esculentum Mill.) seedling growth. Planta 210: 668-676.

Carpin S., Crevecoeur M., Greppin H., Penel C. 1999. Molecular cloning and tissue-specific expression of an anionic peroxidase in zucchini. Plant Physiology 120: 799-810.

Chance B., Maehly A.C. 1955. Assay of catalases and peroxidases. In: Collowick S.P., Kapplan N.O., (eds). Methods in enzymology. Academic Press, New York, (2) pp. 764-775.

Cordewener J., Booij H., Der Zanęt H., Van Engelen F., Van Kammen A., De Fries S. 1991. Tunicamycin-inhibited carrot somatic embryogenesis can be stored by secreted cationic peroxidase isoenzymes. Planta 184: 478-486. 
Feher A., Pasternak T.P., Dudits D. 2003. Transition of somatic plant cells to an embryogenic state. Plant Cell, Tissue and Organ Culture 74: 201-228.

Filonova L.H., Bozhkov P.V., von Arnold S. 2000. Developmental pathway of somatic embryogenesis in Picea abies as revealed by time-lapse tracking. Journal of Experimental Botany 51: 249-264.

Gaj M. 2004. Factors influencing somatic embryogenesis induction and plant regeneration with particular reference to Arabidopsis thaliana (L.) Heynh. Plant Growth Regulation 43: 27-47.

Hazubska-Przybył T., Bojarczuk K. 2008. Somatic embryogenesis of selected spruce species (Picea abies, $P$. omorika, $P$. pungens 'Glauca' and $P$. breweriana). Acta Societatis Botanicorum Poloniae 77: 189-199.

Hřib J., Vooková B., Kormuták A. 1997. Biochemical differences between normal callus and embryogenic suspensor mass of silver fir. Biologia Plantarum 39: 507-513.

Jimenez V.M. 2001. Regulation of in vitro somatic embryogenesis with emphasis on the role of endogenous hormone. Revista Brasileira de Fisiologia Vegetal 13: 196-223.

de Klerk G.J., Arnholdt-Schmitt B., Lieberei R., Neumann K.-H. 1997. Regeneration of roots, shoots and embryos: physiological, biochemical and molecular aspects. Biologia Plantarum 39: 53-66.

Krsnik-Rasol M. 1991. Peroxidase as a developmental marker in plant tissue culture. International Journal of Developmental Biology 35: 259-263.

Kormuták A., Salaj T., Matúšová R., Vooková B. 2003. Biochemistry of zygotic and somatic embryogenesis in silver fir (Abies alba Mill.). Acta Biologica Cracoviensia Series Botanica 45: 59-62.

Litvay J.D., Verma D.C., Johnson M.A. 1985. Influence of loblolly pine (Pinus taeda L.) culture medium and its components on growth and somatic embryogenesis of wild carrot (Daucus carota L.). Plant Cell Reports 4: 325-328.

Mo L.H., Egertsdotter U., Arnold von S. 1996. Secretion of specific extracellular proteins by somatic embryos of Picea abies in dependent on embryo morphology. Annals of Botany 77: 143-152.
Mordhorst A.P., Toonen M.A.J., de Vries S.C. 1997. Plant embryogenesis. Critical Reviews in Plant Sciences 16: 535-576.

Namasivayam P. 2007. Acquisition of embryogenic competence during somatic embryogenesis. Plant Cell, Tissue and Organ Culture 90: 1-8.

Pullman G.S., Chase K.-M., Skryabina A., Bucalo K. 2009. Conifer embryogenic tissue initiation: improvements by supplementation of medium with D-xylose and D-chiro-inositol. Tree Physiology 29: 147-156.

Quiroz-Figueroa F.R., Rojas-Herrera R., Galaz-Avaloz R.M., Loyola-Vargas V.M. 2006. Embryo production through somatic embryogenesis can be used to study cell differentiation in plants. Plant Cell, Tissue and Organ Culture 86: 285-301.

Salajova T., Jasik J., Salaj J. 1998. Somatic embryogenesis in hybrid firs Abies alba $\times$ Abies cephalonica and Abies alba $\times$ Abies numidica. In: Salajova T., Jasik J., Salaj J., (eds). In vitro cultures of conifers. Veda Publishing House of the Slovak Academy of Sciences, Bratislava, pp. 63-69.

Stasolla C., Kong L., Yeung E.C., Thorpe T.A. 2002. Maturation of somatic embryos in conifers: morphogenesis, physiology, biochemistry and molecular biology. In Vitro Cellular and Developmental Biology - Plant 38: 93-105.

Stasolla C., Yeung E.C. 2007. Cellular ascorbic acid regulates the activity of major peroxidases in the apical poles of germinating white spruce (Picea glauca) somatic embryos. Plant Physiology and Biochemistry 45: 188-198.

Sutherland M.W. 1991. The generation of oxygen radicals during host plant responses to infection. Physiological and Molecular Plant Pathology 39: 79-93.

Toonen M.A.J., de Vries S.C. 1996. Initiation of somatic embryos from single cells. In: Wang TL, Cuming A, editors. Embryogenesis: the generation of a plant. Bios Scientific Publishers, Oxford, pp. 173-189.

Vágner M., Fischerová L., Špačková J., Vondráková Z. 2005. Somatic embryogenesis in Norway spruce. W: S.M. Jain, P.K. Gupta (eds), Protocol for somatic embryogenesis in woody plants. Forestry Science 77 (A): pp. 141-155. 